\title{
Safety evaluation of multilane arterials in Florida
}

\author{
Mohamed Abdel-Aty , Prem Chand Devarasetty , Anurag Pande
}

\begin{abstract}
A B S T R A C T
Resurfacing is one of the more common construction activities on highways. While its effect on riding quality on any type of roadway is obviously positive; its impact on safety as measured in terms of crashes is far from obvious. This study examines the safety effects of the resurfacing projects on multilane arterials with partially limited access. Empirical Bayes method, which is one of the most accepted approaches for conducting before-after evaluations, has been used to assess the safety effects of the resurfacing projects. Safety effects are estimated not only in terms of all crashes but also rear-end as well as severe crashes (crashes involving incapacitating and fatal injuries). The safety performance functions (SPFs) used in this study are negative binomial crash frequency estimation models that use the information on ADT, length of the segments, speed limit and number of lanes. These SPFs are segregated by crash groups (all, rear-end, and severe), length of the segments being evaluated, and land use (urban, suburban, and rural). The results of the analysis show that the resulting changes in safety following resurfacing projects vary widely. Evaluating additional improvements carried out with resurfacing activities showed that all (other than sidewalk improvements for total crashes) of them consistently led to improvements in safety of multilane arterial sections. It leads to the inference that it may be a good idea to take up additional improvements if it is cost effective to do them along with resurfacing. It was also found that the addition of turning lanes (left and/or right) and paving shoulders were two improvements associated with a project's relative performance in terms of reduction in rear-end crashes.
\end{abstract}

\section{Introduction}

The resurfacing work improves the quality of ride on roadways by restoring the shape and integrity of the travel surface. The improvements to the quality of ride may be precisely measured in terms of the Present Serviceability Ratings (PSR) estimated based on the AASHTO Road Test (RCI Features and Characteristics Handbook, 2001), before and after the resurfacing projects. Measurement of resulting changes in terms of safety is a more complicated matter. In this regard, the objectives of this study are twofold: (i) estimating the safety effects of resurfacing projects on multilane arterials with the application of a state-of-the-art analytical method and (ii) based on the estimated safety effects of each resurfacing project along with the information on the other tasks completed with the respective project, make inferences on best practices to be undertaken along with the resurfacing process.

In this study, 136 resurfacing projects on multilane arterials (with partially limited access) were investigated for their safety effects between the years 2003 and 2006 in the state of Florida. It is worth mentioning that for all the projects considered for evaluation in this study resurfacing was specified as major or primary work. These projects varied in three critical aspects: land use of the area, length of the section resurfaced, and the additional tasks accompanying the projects (other improvements in addition to resurfacing). There were only 22 projects out of the total 136 projects which did not have any additional work involved other than resurfacing. The methodology adopted herein to assess the safety effects of these projects is the empirical Bayes (EB) method proposed by Hauer (1997), which is documented to be a much better alternative to the naïve before-after evaluations. It provides a more reliable estimate of the change in safety after a project (Persaud and Lyon, 2007). Once the EB estimate of change in safety is obtained; the "best" and "worst" projects are identified and further examined for the activities undertaken with these projects besides resurfacing itself. The relative distributions of these activities such as adding lanes, shoulder paving, etc., within the "best" and "worst" projects are then used to infer which of these activities should be recommended when the work orders for resurfacing projects are issued.

The paper is organized as follows: the next section provides a background of the studies evaluating before-after safety effects of an 'improvement' with a focus on the resurfacing projects. The sections after that briefly describe the development of safety performance functions (SPFs) and the EB methodology. These SPFs 
are then used in the following section to get the estimates of the safety effects for all resurfacing projects. The inference about activities that should be undertaken with the resurfacing projects is then made based on the activities' associations with the "best" and "worst" projects. The last section then comprises of the overall conclusions and directions of future research.

\section{Background}

Cleveland (1987) documented considerable information on the safety effects of two aspects of pavements condition improved by resurfacing projects: pavements roughness and skid resistance. The study emphasized the need to further study the safety effects of resurfacing with state-of-the-art experimental/analytical methods.

Since the study by Cleveland (1987) there have been some studies that undertook the task of assessing the impact of resurfacing. Hauer et al. (1994) studied the resurfacing projects on two-lane rural roads in the state of New York using the empirical Bayes (EB) method. The study revealed that for the projects involving only resurfacing the safety initially declined (possibly due to drivers choosing higher speeds due to changed visual cues provided by the resurfaced facility). For projects involving resurfacing with other additional improvements the safety, in fact, improved. McGee et al. (1995) identified lack of understanding of the impact of resurfacing on safety with additional improvements as a critical gap in understanding of influence of design features on safety.

In this regard, Hughes et al. (2001) aimed at determining the impacts of resurfacing with and without additional safety improvements. They studied resurfacing projects that were carried out in five states. The scope of that research, however, was limited to two-lane roads in rural and suburban areas with no access control and posted speed limits more than $45 \mathrm{mph}$. Although the results of the study were not thoroughly conclusive the effects of resurfacing were found to vary by state possibly due to differences in the individual site characteristics. Multilane arterials with partial access control (signalized as well as unsignalized access points) are more complicated and therefore require much more careful data preparation. The issues that need to be addressed in this regard are discussed (and addressed) in this study.

None of the previous studies had any conclusive results on how additional improvements, when coupled with resurfacing, affect the safety on multilane arterials with partial access control. It provided the motivation for the present study. Based on recommendation from Cleveland (1987) an extensive literature review was conducted to identify the state-of-the-art analytical practice to conduct before/after evaluations. A summary of this review is provided in the next section.

\section{Methodologies for before-after evaluations}

The safety evaluation of any treatment applied to a site should compare the observed number (or rate, etc.) of crashes (of a given type) on that site after the treatment with the number of crashes that would have occurred in the after period had the treatment not been applied. Harwood et al. (2003) documented that there are three common ways to carry out the evaluations of treatments in terms of their safety effects:

- Naïve before-after evaluation,

- before-after evaluation with a comparison group (CG), and

- before-after evaluation by the empirical Bayes (EB) approach.

The naïve before-after study involves simple comparison of crash frequencies/rates between the before and after periods of the treatment site. As Hauer (1997) pointed out the number of crashes that were reported in the before period by itself is not a good estimate for 'number of crashes that would have occurred in the after period had the treatment not been applied'. The reasons include the changes in safety that may result from changes in traffic volume as well as the regression-to-the-mean phenomenon (Persaud and Lyon, 2007).

The before-after evaluation with a comparison group uses, as the name suggests, a comparison group to estimate the number of crashes at the treatment site, had the treatment had not been applied. These expected numbers of crashes are then compared to the observed number of crashes at the treatment site. The comparison group here refers to the group of sites "similar" to the treatment site at which the treatment is not applied. These comparison groups need to be sampled prior to the application of the treatment (resurfacing in the context of the present study). In fact, similar sites need to be selected and randomly assigned as 'treatment group' and 'comparison group' before any treatments are applied. Harwood et al. (2003) explained the differences in evaluation based each of the above methods and the limitations of each method.

Another issue with the comparison group method is that it does not account for the changes in safety resulting from the fact that treated sites might attract more volume of traffic because of the improvement (e.g., more people may prefer to drive on a newly paved road) (Hauer, 1997). The EB method can overcome the limitations faced by other methods by not only accounting for RTM effects, but also accounts for traffic volume changes (Hauer, 1997). Moreover, in this study resurfacing projects already completed by the Florida Department of Transportation (FDOT) are being evaluated. The process of randomly assigning sites into 'treatment' and 'comparison' group could not be carried out in the context of this research problem. It left the EB as the most suitable approach for this study.

For the EB method, the expected number of crashes at the treatment site in the after period had the treatment not been made, is estimated from two clues; the crash history of the treatment site and the crash frequency expected at reference sites (Hauer, 1997). These expected crash frequencies at similar entities are estimated using SPFs. An SPF is nothing but a crash prediction model, which relates the frequency of crashes to the roadway characteristics (shoulder width, width of lanes, number of lanes, etc.) and traffic parameters (average daily traffic) of that roadway section. The SPFs estimated by Shen (2007) for multilane arterials in FL only included ADT as the factor. In this study "full" SPFs are developed and applied with more parameters than just the ADT. Moreover, 27 different SPFs (breakdown is provided in the next section; see Fig. 1) are estimated separately by segregating the crash data by land-use and segment lengths for total, rear-end, and severe crash groups.

\section{Data preparation and safety performance functions}

Two sets of data are used in this study: (i) information from the sites where treatment (resurfacing) was applied and (ii) information from reference sites to develop the SPFs. The information on all resurfacing projects on multilane arterials that were initiated and completed between the years 2003 and 2006 in the state of Florida were collected first. To focus on the segments of multilane arterials with partially limited access all projects for which resurfacing was done on a segment of length less than $1 / 2$ mile were excluded from this evaluation. The data were collected from FDOT's financial project search website (FDOT, 2007) available on the intranet. For each of the 136 projects the collected information included start date, end date, roadway id, beginning mile-post, ending milepost, number of lanes, and additional improvements accompanying resurfacing. The lengths of the segments vary from 0.5 to 8.7 miles. The information on additional improvements was collected from 


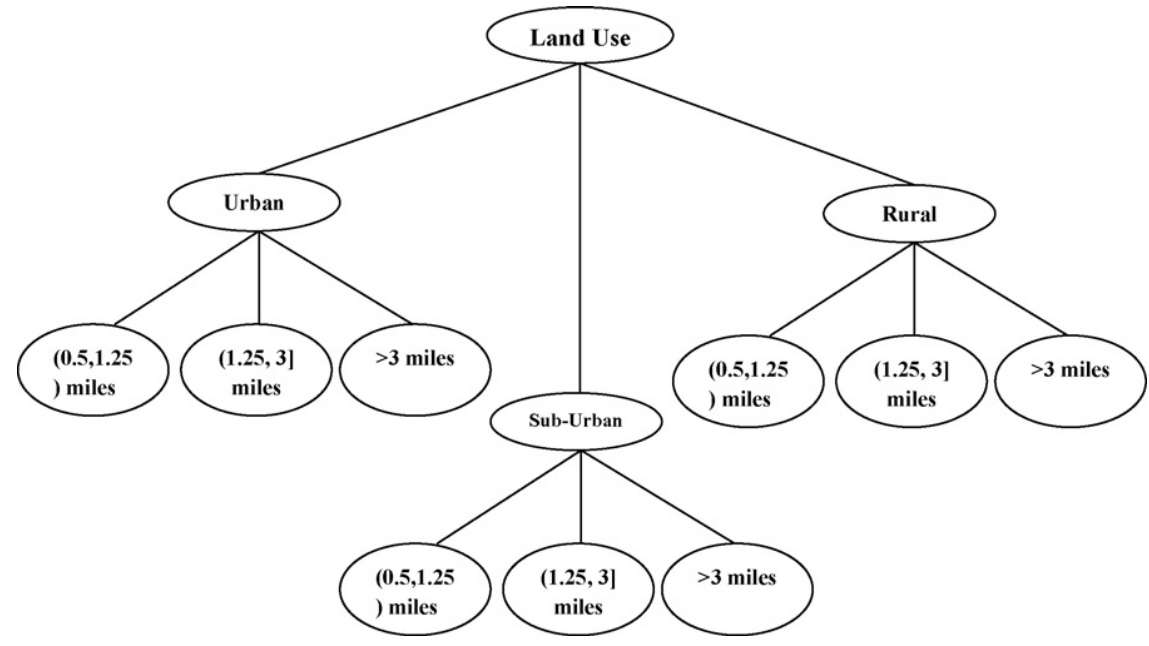

Fig. 1. Nine groups of SPFs estimated for total, rear-end, and severe crashes.

the contract documents and project plans belonging to the projects. The contract documents and project plans were accessed from FDOT's intranet (FDOT, 2008). A total of 15 common improvements which were done in conjunction with resurfacing were identified. These improvements include signal installation, widening the road, guardrail improvement/installation, adding turning lanes, etc. These improvements and their percentages for the 136 projects are provided in Table 1 . It may be observed that adding lanes and median widening are two of the least common additional improvements while drainage improvement and signal update are two of the most common ones.

The crash data for the aforementioned projects during the before (from January 2002 till project beginning date) and after periods (from project end date till December 2007) of the treatment were collected from the Crash Analysis Reporting System (CAR), and the geometric characteristics and traffic volumes were extracted from Roadway Characteristics Inventory (RCI) database. The data on crashes were segregated into three types: total number of crashes, severe crashes (incapacitating and fatal), and rear-end crashes. Since not all projects had the same start and end date, they had a different before and after period durations for which crash data were collected. The average durations for the 'before' and 'after' periods corresponding to all projects were 1113 and 797 days, respectively. In all, there were 20,749 crashes observed in the before period (corresponding to all projects), of which 1853 were characterized as severe and 7411 were of the rear-end type. The total number of crashes observed in the after periods

Table 1

Percentage of projects involving each of the additional improvements.

\begin{tabular}{lc}
\hline Type of improvement & \% of projects involving the improvement \\
\hline Add lane & 0.74 \\
Median widening & 3.68 \\
Add shoulder & 4.41 \\
Signal installation & 5.15 \\
Access improvement & 5.15 \\
Guardrail installation & 6.62 \\
Add right turn lane & 8.82 \\
Add left turn lane & 10.29 \\
Guardrail improvement & 13.24 \\
Lighting improvement & 14.71 \\
Pave shoulder & 16.91 \\
Sidewalk & 23.53 \\
Widening & 31.62 \\
Drainage improvement & 40.44 \\
Signal update & 43.38
\end{tabular}

corresponding to all projects were 14,331 ; of which 1244 were characterized as severe and 5074 were of the rear-end type. It is worth mentioning that disaggregate SPFs corresponding to these three groups of crashes were estimated for the analysis conducted in this study.

The next step in data collection was to collect the information on the reference sites. Continuous roadway sections of multilane arterials having the same number of lanes and speed limit were identified from the state of Florida. A total 2780 of such sections are identified which varied from 0.1 to 25 miles in length. These sections were then limited to those sections having the same length range as the resurfacing projects. The number of sections which fell in the length range of the resurfacing projects was 1758. The crash data, geometric and traffic characteristics for these sections are obtained from the aforementioned CAR and RCI databases.

It is worth mentioning that the access density was considered a potential variable in the SPF, but the precise information on the corresponding variable was found to be missing in the database. Fortunately, the information, where available, was strongly correlated with land use (urban, sub-urban, and rural). Therefore, the reference sites were separated according to their land use and SPFs were generated using SAS for each land use category and length group. The above classification resulted in 9 different SPFs for each crash type. Fig. 1 illustrates the classification tree used in developing the SPFs.

First, nine different negative binomial crash frequency estimation models were estimated (for each of the three different crash types and three land use categories). These models were compared with models that were estimated for different length groups (with arbitrary thresholds; e.g., $0.5-1.5,1.5-3$ miles and so on). It was observed that the coefficients of the parameters varied significantly from the overall model(s) and for models with disaggregated length groups. Hence, it was decided to fit several models based on different length groups. The length thresholds were determined by clustering the section lengths of the 136 different resurfacing projects into three clusters: $(0.5,1.25)$ miles $(>1.25,3)$ miles, and greater than 3 miles. Table 2 shows the descriptive statistics of the reference group.

Disaggregating SPFs by lengths of the resurfaced sections under examination is advantageous for one more reason. The over-dispersion parameter estimated for the negative binominal regression model is suspected to vary by lengths of the segments under consideration (Hauer, 2001). Using SPFs segregated into three different length groups ensures that the assumption of a constant 
Table 2

Descriptive statistics of the Corridors Reference group.

\begin{tabular}{|c|c|c|c|}
\hline & $0.5<$ section length $\leq 1.5$ & $1.5<$ section length $\leq 3.0$ & $3.0<$ section length $\leq 9.0$ \\
\hline Number of sections & 690 & 624 & 344 \\
\hline Minimum ADT & 1000 & 3300 & 2700 \\
\hline Average ADT & 26630.47 & 30359.71 & 29447.32 \\
\hline Maximum ADT & 89,500 & 87,950 & 93,587 \\
\hline Minimum (total crashes/year) & 0 & 0 & 0 \\
\hline Average (total crashes/year) & 20.08 & 52.14 & 107.25 \\
\hline Maximum (total crashes/year) & 225 & 489 & 785 \\
\hline Minimum (severe crashes/year) & 0 & 0 & 0 \\
\hline Average (severe crashes/year) & 1.68 & 4.58 & 9.35 \\
\hline Maximum (severe crashes/year) & 23 & 42 & 60 \\
\hline Minimum (rear-end crashes/year) & 0 & 0 & 0 \\
\hline Average (rear-end crashes/year) & 7.24 & 19.26 & 39.45 \\
\hline Maximum (rear-end crashes/year) & 97 & 146 & 390 \\
\hline
\end{tabular}

dispersion parameter is not violated in a serious way. Nine groups of SPFs developed for each crash group (total, severe, and rear-end crashes) are depicted in Fig. 1.

The following step is to estimate SPFs for each crash type from the information from the reference sites. Using PROC GENMOD procedure in SAS (2008), negative binomial models were fitted for the frequency of crashes with the explanatory variables ADT, length of the section, number of lanes, and speed limit. Of the explanatory variables, logarithms of ADT and section lengths were measured on a continuous scale and number of lanes and speed limit were used as nominal variables. Number of levels for categorical variables considered are three (for number of lanes-4 lanes, 5 lanes, and 6 lanes), and six (for speed limit-with thresholds on $40,45,50$, 55,60 , and $65 \mathrm{mph}$ ).

With three different groups of crashes (total, severe, and rearend) there were a total of 27 different SPFs that were estimated. Table 3 shows the coefficients for negative binomial models for total crashes for each of the nine aforementioned categories. It can be seen from the table that not all of the explanatory variables are significant in all the models. For example number of lanes is not a significant variable for sections' lengths more than 1.25 miles. It may also be observed that the coefficients for the same variables vary widely across the models. It indicates that the approach of separate models for each category is indeed a better one.

It is also worth mentioning that the number of severe crashes was very low for rural sections of lengths $0.5-1.25$ miles. To ensure that a meaningful sample size is available to estimate the negative binomial regression models rural sections of lengths between 0.5 and 1.25 miles were combined with the suburban sections of the same length groups (hence identical coefficients in corresponding rows of Table 4). Except for urban sections with less than 3 miles, in all other SPFs speed limit was found not to be significant in the models for severe crashes. Number of lanes is found not to be significant in all the SPFs.

Rear-end crashes are the most common type of crashes characterized based on first harmful event. These crashes may be related to the skid resistance of the pavement which is directly affected by resurfacing. Table 5 shows the parameter estimates for rear-end crashes. It can be seen from the table that the number of lanes was not significant in any of the models. The next part of the paper discusses the application of the EB method to the projects and the results.

\section{Empirical Bayes methodology}

This section illustrates the steps involved in the evaluation process after obtaining the crash frequency estimates from the SPFs estimated in the last section. The EB method combines two different sets of 'evidence' to estimate the number of crashes at the treatment site, which can be written in the mathematical form as follows (Hauer, 1997):

$\hat{E}_{i}=\left(\gamma_{i} \times y_{i} \times n\right)+\left(1-\gamma_{i}\right) \eta_{i}$

where $\hat{E}_{i}=\mathrm{EB}$ estimate of the crashes at the treatment site in the before period, $\eta_{i}=$ observed number of crashes at the treatment site during the before period (represents the 'evidence' from the treatment sites). $n=$ number of years in the before period,

$\gamma_{i}=\frac{1}{1+k \times y_{i} \times n}$

$k=$ dispersion parameter, $y_{i}=$ number of average expected crashes of given type per year estimated from the SPF (represents the 'evidence' from the reference sites).

Crash frequency on a roadway section may be estimated using negative binomial regression models (Abdel-Aty and Radwan, 2000; Persaud, 1990), and therefore it is the form of the SPFs for negative binomial model is used to fit the before period crash data of the reference sites with their geometric and traffic parameters. A typical SPF will be of the following form:

$y_{i}=\mathrm{e}^{\left(\beta_{0}+\beta_{1} x_{1}+\beta_{2} x_{2}+\cdots+\beta_{n} x_{n}\right)}$

where $\beta_{i}$ = regression parameters, $x_{1}$ and $x_{2}$ here are logarithmic values of AADT and section length, $x_{i}(i>2)=$ other traffic and geometric parameters of interest.

Over-dispersion parameter, denoted by $k$ is the parameter which determines how widely the crash frequencies are dispersed around the mean. This is used to estimate the relative weight of the two sets of evidences (Eqs. (1) and (2)). by

And the standard deviation $\left(\sigma_{i}\right)$ for the estimate in Eq. (1) is given

$\hat{\sigma}_{i}=\sqrt{\left(1-\gamma_{i}\right) \times \hat{E}_{i}}$

The estimates obtained from Eq. (1) are the estimates for number of crashes in the before period. Since, it is required to get the estimated number of crashes at the treatment site in the after period; the estimates obtained from Eq. (1) are to be adjusted for traffic volume changes and different before and after periods (Hauer, 1997; Noyce et al., 2006). The adjustment factors for which are given as below

Adjustment for AADT $\left(\rho_{A A D T}\right)$ :

$\rho_{\text {AADT }}=\frac{A A D T_{\text {after }}^{\alpha_{1}}}{A A D T_{\text {before }}^{\alpha_{1}}}$

where $A A D T_{\text {after }}=\mathrm{AADT}$ in the after period at the treatment site, and $A A D T_{\text {before }}=\mathrm{AADT}$ in the before period at the treatment site.

Adjustment for different before-after periods $\left(\rho_{\text {time }}\right)$ :

$\rho_{\text {time }}=\frac{m}{n}$

where $m=$ number of years in the after period. 
Table 3

SPFs for total crashes by each category.

\begin{tabular}{|c|c|c|c|c|c|c|c|c|c|c|}
\hline \multicolumn{11}{|c|}{ Total Crashes } \\
\hline \multirow{3}{*}{\multicolumn{2}{|c|}{ Parameter }} & \multicolumn{3}{|c|}{0.5 miles $<$ total length $\leq 1.25$ miles } & \multicolumn{3}{|c|}{1.25 miles $<$ total length $\leq 3$ miles } & \multicolumn{3}{|c|}{$>3$ miles } \\
\hline & & Urban & Sub-Urban & Rural & Urban & Sub-Urban & Rural & Urban & Sub-Urban & Rural \\
\hline & & $\begin{array}{l}\text { Estimate } \\
\text { (p-value) }\end{array}$ & $\begin{array}{l}\text { Estimate } \\
\text { ( } p \text {-value) }\end{array}$ & $\begin{array}{l}\text { Estimate } \\
(p \text {-value) }\end{array}$ & $\begin{array}{l}\text { Estimate } \\
\text { ( } p \text {-value) }\end{array}$ & $\begin{array}{l}\text { Estimate } \\
\text { ( } p \text {-value) }\end{array}$ & $\begin{array}{l}\text { Estimate } \\
(p \text {-value) }\end{array}$ & $\begin{array}{l}\text { Estimate } \\
\text { (p-value) }\end{array}$ & $\begin{array}{l}\text { Estimate } \\
\text { (p-value) }\end{array}$ & $\begin{array}{l}\text { Estimate } \\
\text { (p-value) }\end{array}$ \\
\hline Intercept & & $-6.596(<0.0001)$ & $-8.641(<0.0001)$ & $-4.118(0.0500)$ & $-9.510(<0.0001)$ & $-8.909(<0.0001)$ & $-15.09(<0.0001)$ & $-8.163(<0.0001)$ & $-10.32(<0.0001)$ & $-7.308(<0.0001)$ \\
\hline $\log (\mathrm{ADT})$ & & $0.992(<0.0001)$ & $1.146(<0.0001)$ & $0.680(0.0015)$ & $1.278(<0.0001)$ & $1.171(<0.0001)$ & $1.392(<0.0001)$ & $1.128(<0.0001)$ & $1.295(<0.0001)$ & $0.974(<0.0001)$ \\
\hline log(length) & & $0.931(<0.0001)$ & $0.854(<0.0001)$ & $1.138(0.0074)$ & $1.009(<0.0001)$ & $0.934(<0.0001)$ & $1.282(0.0010)$ & $1.243(<0.0001)$ & $0.915(<0.0001)$ & $0.806(0.0004)$ \\
\hline Speed limit & 65 & - & $0.207(0.7192)$ & $-1.790(0.0002)$ & - & $-1.013(0.0018)$ & $2.574(0.0020)$ & - & $-0.450(0.2994)$ & $-0.650(0.0230)$ \\
\hline Speed limit & 60 & - & $-1.886(0.0604)$ & $-0.829(0.1934)$ & $-1.232(0.0014)$ & $-1.370(<0.0001)$ & $3.005(0.0004)$ & - & $-1.122(0.0122)$ & $-0.872(0.1150)$ \\
\hline Speed limit & 55 & $-1.783(<0.0001)$ & $-0.837(<0.0001)$ & $-0.729(0.0061)$ & $-1.396(<0.0001)$ & $-0.690(<0.0001)$ & $2.67(0.0010)$ & $-1.084(0.0034)$ & $-0.617(0.0716)$ & $-0.542(0.0306)$ \\
\hline Speed limit & 50 & $-1.372(<0.0001)$ & $-0.324(0.1393)$ & $0.337(0.3397)$ & $-1.01(<0.0001)$ & $-0.187(0.2775)$ & $2.818(0.0010)$ & $-1.104(<0.0001)$ & $-0.022(0.0952)$ & $-0.987(0.1949)$ \\
\hline Speed limit & 45 & $-0.585(<0.0001)$ & $-0.126(0.5240)$ & 0 & $-0.446(<0.0001)$ & $-0.158(0.3184)$ & $3.520(<0.0001)$ & $-0.575(<0.0001)$ & $0.106(0.0761)$ & 0 \\
\hline Speed limit & 40 & 0 & 0 & - & 0 & 0 & 0 & 0 & 0 & - \\
\hline \# of lanes & 6 & $0.268(0.0049)$ & $0.245(0.008)$ & $-0.092(0.048)$ & - & - & - & - & - & - \\
\hline \# of lanes & 5 & $0.554(0.0590)$ & $0.110(0.074)$ & - & - & - & - & - & - & - \\
\hline \# of lanes & 4 & 0 & 0 & 0 & - & - & - & - & - & - \\
\hline Dispersion & & 0.454 & 0.466 & 0.650 & 0.311 & 0.237 & 0.419 & 0.250 & 0.416 & 0.232 \\
\hline
\end{tabular}

(Base casesfor the variables measured on nominal scale are highlighted) 
Table 4

SPFs for severe crashes by each category.

\begin{tabular}{|c|c|c|c|c|c|c|c|c|c|c|}
\hline \multicolumn{11}{|c|}{ Severe Crashes } \\
\hline \multirow{3}{*}{\multicolumn{2}{|c|}{ Parameter }} & \multicolumn{3}{|c|}{0.5 miles $<$ total length $\leq 1.25$ miles } & \multicolumn{3}{|c|}{1.25 miles $<$ total length $\leq 3$ miles } & \multicolumn{3}{|c|}{$>\mathbf{3}$ miles } \\
\hline & & Urban & Sub-Urban & Rural & Urban & Sub-Urban & Rural & Urban & Sub-Urban & Rural \\
\hline & & $\begin{array}{l}\text { Estimate } \\
(p \text {-value })\end{array}$ & $\begin{array}{l}\text { Estimate } \\
(p \text {-value) }\end{array}$ & $\begin{array}{l}\text { Estimate } \\
\text { (p-value) }\end{array}$ & $\begin{array}{l}\text { Estimate } \\
(p \text {-value) }\end{array}$ & $\begin{array}{l}\text { Estimate } \\
(p \text {-value })\end{array}$ & $\begin{array}{l}\text { Estimate } \\
\text { (p-value) }\end{array}$ & $\begin{array}{l}\text { Estimate } \\
\text { (p-value) }\end{array}$ & $\begin{array}{l}\text { Estimate } \\
(p \text {-value) }\end{array}$ & $\begin{array}{l}\text { Estimate } \\
\text { (p-value) }\end{array}$ \\
\hline Intercept & & $-7.258(<0.0001)$ & $-6.446(<0.0001)$ & $-6.446(<0.0001)$ & $-7.531(<0.0001)$ & $-9.967(<0.0001)$ & $-8.763(0.0007)$ & $-6.670(<0.0001)$ & $-10.86(<0.0001)$ & $-9.018(<0.0001)$ \\
\hline $\log (\mathrm{ADT})$ & & $1.022(<0.0001)$ & $0.684(<0.0001)$ & $0.684(<0.0001)$ & $1.108(<0.0001)$ & $1.016(<0.0001)$ & $0.903(0.0006)$ & $0.757(<0.0001)$ & $1.118(<0.0001)$ & $1.017(<0.0001)$ \\
\hline log(length) & & $1.130(<0.0001)$ & $0.592(0.0213)$ & $0.592(0.0213)$ & $0.903(<0.0001)$ & $1.191(<0.0001)$ & $0.887(0.0742)$ & $1.007(<0.0001)$ & $0.865(0.0003)$ & $0.301(0.2327)$ \\
\hline Speed limit & 65 & - & - & - & - & - & - & - & - & - \\
\hline Speed limit & 60 & - & - & - & $-1.858(0.0782)$ & - & - & - & - & - \\
\hline Speed limit & 55 & $-1.340(0.0432)$ & - & - & $-0.257(0.0344)$ & - & - & & - & - \\
\hline Speed limit & 50 & $-0.466(0.0794)$ & - & - & $-0.567(0.0006)$ & - & - & & - & - \\
\hline Speed limit & 45 & $-0.234(0.0398)$ & - & - & $-0.101(0.2225)$ & - & - & & - & - \\
\hline Speed limit & 40 & 0 & - & - & 0 & - & - & & - & - \\
\hline \# of lanes & 6 & & - & - & & - & - & - & - & - \\
\hline \# of lanes & 5 & & - & - & & - & - & - & - & - \\
\hline \# of lanes & 4 & & - & - & & - & - & - & - & - \\
\hline Dispersion & & 0.396 & 0.679 & 0.679 & 0.309 & 0.148 & 0.683 & 0.196 & 0.342 & 0.149 \\
\hline
\end{tabular}

(Base cases for the variables measured on nominal scale are highlighted) 
Table 5

SPFs for rear-end crashes by each category.

\begin{tabular}{|c|c|c|c|c|c|c|c|c|c|c|}
\hline \multicolumn{11}{|c|}{ Rear-end Crashes } \\
\hline \multirow{3}{*}{\multicolumn{2}{|c|}{ Parameter }} & \multicolumn{3}{|c|}{0.5 miles $<$ total length $\leq 1.25$ miles } & \multicolumn{3}{|c|}{1.25 miles $<$ total length $\leq 3$ miles } & \multicolumn{3}{|c|}{$>3$ miles } \\
\hline & & Urban & Sub-Urban & Rural & Urban & Sub-Urban & Rural & Urban & Sub-Urban & Rural \\
\hline & & $\begin{array}{l}\text { Estimate } \\
\text { (p-value) }\end{array}$ & $\begin{array}{l}\text { Estimate } \\
(p \text {-value) }\end{array}$ & $\begin{array}{l}\text { Estimate } \\
(p \text {-value) }\end{array}$ & $\begin{array}{l}\text { Estimate } \\
\text { ( } p \text {-value) }\end{array}$ & $\begin{array}{l}\text { Estimate } \\
(p \text {-value) }\end{array}$ & $\begin{array}{l}\text { Estimate } \\
\text { (p-value) }\end{array}$ & $\begin{array}{l}\text { Estimate } \\
\text { (p-value) }\end{array}$ & $\begin{array}{l}\text { Estimate } \\
\text { ( } p \text {-value) }\end{array}$ & $\begin{array}{l}\text { Estimate } \\
\text { (p-value) }\end{array}$ \\
\hline Intercept & & $-14.69(<0.0001)$ & $-14.68(<0.0001)$ & $-13.214(0.0001)$ & $-14.54(<0.0001)$ & $-15.33(<0.0001)$ & $-23.93(<0.0001)$ & $-12.20(<0.0001)$ & $-17.58(<0.0001)$ & $-14.82(<0.0001)$ \\
\hline $\log (\mathrm{ADT})$ & & $1.672(<0.0001)$ & $1.607(<0.0001)$ & $1.468(<0.0001)$ & $1.642(<0.0001)$ & $1.689(<0.0001)$ & $2.475(<0.0001)$ & $1.407(<0.0001)$ & $1.892(<0.0001)$ & $1.636(<0.0001)$ \\
\hline $\log$ (length) & & $0.824(<0.0001)$ & $0.696(0.0063)$ & $0.851(0.2127)$ & $1.174(<0.0001)$ & $0.905(<0.0001)$ & $0.855(0.0951)$ & $1.197(<0.0001)$ & $0.845(0.0015)$ & $0.829(0.0117)$ \\
\hline Speed limit & 65 & - & - & $-2.761(0.0201)$ & - & $-1.282(0.0053)$ & - & - & $-0.602(0.2474)$ & $-1.079(0.0987)$ \\
\hline Speed limit & 60 & - & - & $-0.840(0.4273)$ & $-1.602(0.0070)$ & $-2.396(<0.0001)$ & - & - & $-1.403(0.0135)$ & $-1.539(0.0228)$ \\
\hline Speed limit & 55 & $-2.009(<0.0001)$ & - & $-0.733(0.0815)$ & $-1.065(<0.0001)$ & $-0.646(0.0012)$ & - & $-0.742(0.0453)$ & $-0.399(0.3167)$ & $-1.054(0.0956)$ \\
\hline Speed limit & 50 & $-1.229(<0.0001)$ & - & $0.423(0.4276)$ & $-0.903(<0.0001)$ & $-0.069(0.7428)$ & - & $-0.761(<0.0001)$ & $0.221(0.0616)$ & $-1.122(0.2372)$ \\
\hline Speed limit & 45 & $-0.452(<0.0001)$ & - & 0 & $-0.348(<0.0001)$ & $0.014(0.0942)$ & - & $-0.362(<0.0001)$ & $0.401(0.3235)$ & 0 \\
\hline Speed limit & 40 & 0 & - & - & 0 & 0 & - & 0 & 0 & - \\
\hline \# of lanes & 6 & - & - & - & - & - & - & - & - & - \\
\hline \# of lanes & 5 & - & - & - & - & - & - & - & - & - \\
\hline \# of lanes & 4 & - & - & - & - & - & - & - & - & - \\
\hline Dispersion & & 0.450 & 0.793 & 1.232 & 0.287 & 0.324 & 0.726 & 0.231 & 0.534 & 0.299 \\
\hline
\end{tabular}

(Base cases for the variables measured on nominal scale are highlighted) 
Final estimated number of crashes at the treatment location in the after period $\left(\hat{\pi}_{i}\right)$ after adjusting for traffic volume changes and different time periods is given by

$\hat{\pi}_{i}=\hat{E}_{i} \times \rho_{\text {AADT }} \times \rho_{\text {time }}$

The index of effectiveness $\left(\theta_{i}\right)$ of the treatment is given by

$\hat{\theta}_{i}=\frac{\hat{\lambda}_{i} / \hat{\pi}_{i}}{1+\left(\hat{\sigma}_{i}^{2} / \hat{\pi}_{i}^{2}\right)}$

where $\hat{\lambda}_{i}=$ observed number of crashes at the treatment site during the after period.

The percentage reduction $\left(\tau_{i}\right)$ in crashes of particular type at each site $i$ is given by

$\hat{\tau}_{i}=\left(1-\hat{\theta}_{i}\right) \times 100 \%$

The effectiveness $(\hat{\theta})$ of the treatment (resurfacing) averaged over all resurfacing projects would be given by (Persaud et al., 2004)

$\hat{\theta}=\frac{\sum_{i=1}^{m} \hat{\lambda}_{i} / \sum_{i=1}^{m} \hat{\pi}_{i}}{1+\left(\operatorname{var}\left(\sum_{i=1}^{m} \hat{\pi}_{i}\right) /\left(\sum_{i=1}^{m} \hat{\pi}_{i}\right)^{2}\right)}$

where $m=$ total number of projects $=136$

The standard deviation $(\sigma)$ of the overall effectiveness may be estimated using information on the variance of the estimated and observed crashes. With percentage reduction in crashes for each site (for each crash type) the worst $25 \%$ and best $25 \%$ projects in terms of their performance in the crash reduction are selected and analyzed for different type of additional treatments involved in the projects. Based on the analysis conclusion will be drawn on which additional improvements are better in terms of improving safety.

\section{Analysis and results}

The EB method explained above was applied for all the 136 resurfacing projects under consideration. The SPFs were used according to the project lengths for estimating the expected number of crashes at the treatment sites in the before period and necessary correction factors were applied to obtain the predicted values in the after period. Three overall indices of effectiveness (corresponding to total, rear-end and severe crashes) were estimated by Eq. (10). Based on these indices and the overall percentage reduction in the numbers of crashes were also calculated along with corresponding standard errors. Table 6 shows the overall percentage reductions obtained from the EB approach. The results showed an increase of $0.62 \%$ in total number of crashes at the treatment sites. Rear-end crashes were reduced by an estimate of 0.83 and severe crashes were reduced by an estimate of $4.63 \%$. It is important to note that while there was a significant reduction in severe as well as rearend crashes; the estimates from individual projects varied widely. Apart from rear-end crashes, wet-pavement crashes may be another way to check for the safety effect of the resurfacing projects resulting from improved skid resistance of the roadway section being treated. Hence, the percentage of total crashes which are related to wet-pavement are calculated in both of the before and after period to check for any differences. It was found that $13.88 \%$ and $11.14 \%$ of total crashes were related to wet-pavement in the before and after periods, respectively. Although there is a slight decrease in the proportion of wet-pavement related crashes in the after period, this reduction cannot directly be attributed to the improved surface condition of the road as there may be a possibility that the reductions are just due to less rainy days in the after period.

The next step was to examine the results of EB analysis for individual projects. Table 7 shows a sample of results (for $14(\sim 10 \%)$ out of the total 136 projects) based on total crashes. Tabulated information includes length of the section resurfaced, binary variables indicating presence of additional treatments, observed number of total crashes in the after period, EB estimate of total crashes in the after period (had no treatment been applied) along with index of effectiveness and estimated percentage reduction in total crashes.

Of the 136 projects under consideration, $57.35 \%$ of them had a reduction in the total number of crashes, $71.32 \%$ of them had a reduction in the number of severe crashes, and $59.56 \%$ had a reduction in number of rear-end crashes. It was found that the reductions in total, severe, and rear-end crashes were not correlated with the lengths of the segments.

The percentage reductions in the number of crashes were used to identify the best and worst $25 \%$ projects based on each crash type. Note that some of the project sites in the bottom quartile (i.e., worst $25 \%$ projects) actually observed higher crashes after improvement (based on actual 'after' crash frequency) compared to the estimated number that would have occurred had the resurfacing not been carried out. To examine the effects of the additional improvements (listed in Table 1), proportions of projects with a particular improvement were calculated among best $25 \%$ and worst $25 \%$ projects. These two proportions were then compared with proportion of projects with that particular improvement in all (i.e., 136) projects.

Bar charts were created to depict comparisons between these three proportions. Figs. 2-4 correspond to total, severe, and rearend crashes, respectively. If the proportion of projects involving a particular improvement the best $25 \%$ is more than the proportion of projects involving the same treatment in the worst $25 \%$ as well as all projects (i.e., 136 total project being evaluated); then the improvement/treatment can be considered to be a good practice to go along with resurfacing. For example, in terms of total crashes (Fig. 2) the proportions of resurfacing projects with lighting improvements in the best and worst quartiles are $33 \%$ and $6 \%$, respectively. It implies that resurfacing projects with accompanying lighting improvements are more likely to lead to reduction in overall crashes. Using this logic it can be inferred that signal installation, guardrail improvement, drainage improvement, adding turn lanes (left and/or right), and access improvement are good practices which when done along with resurfacing are likely to lead to reduction in total crashes. Note that for all these improvements the bar corresponding to "best 25\%" are higher in Fig. 2 compared to the bar corresponding to "worst 25\%". Similarly, for severe crashes guardrail improvement and lighting improvement appear to be good candidates for additional improvements to be carried out with resurfacing (see Fig. 3). For rear-end crashes, guardrail improvement, shoulder paving, drainage improvement, adding right or left turn lane, lighting improvement, and access improvement may be considered good practices (see Fig. 4).

Table 6

Overall indices of effectiveness for resurfacing projects by crash type.

\begin{tabular}{|c|c|c|c|}
\hline \multicolumn{4}{|c|}{ Total number of projects $=136$} \\
\hline & Overall index of effectiveness (EB) & Percentage reduction (EB) & Standard deviation of index of effectiveness (EB) \\
\hline Total crashes & 1.00625 & -0.625 & 0.01627 \\
\hline Severe crashes & 0.95367 & 4.633 & 0.045801 \\
\hline Rear-end crashes & 0.9917 & 0.83 & 0.026491 \\
\hline
\end{tabular}


Table 7

Sample results from EB method for total crashes.

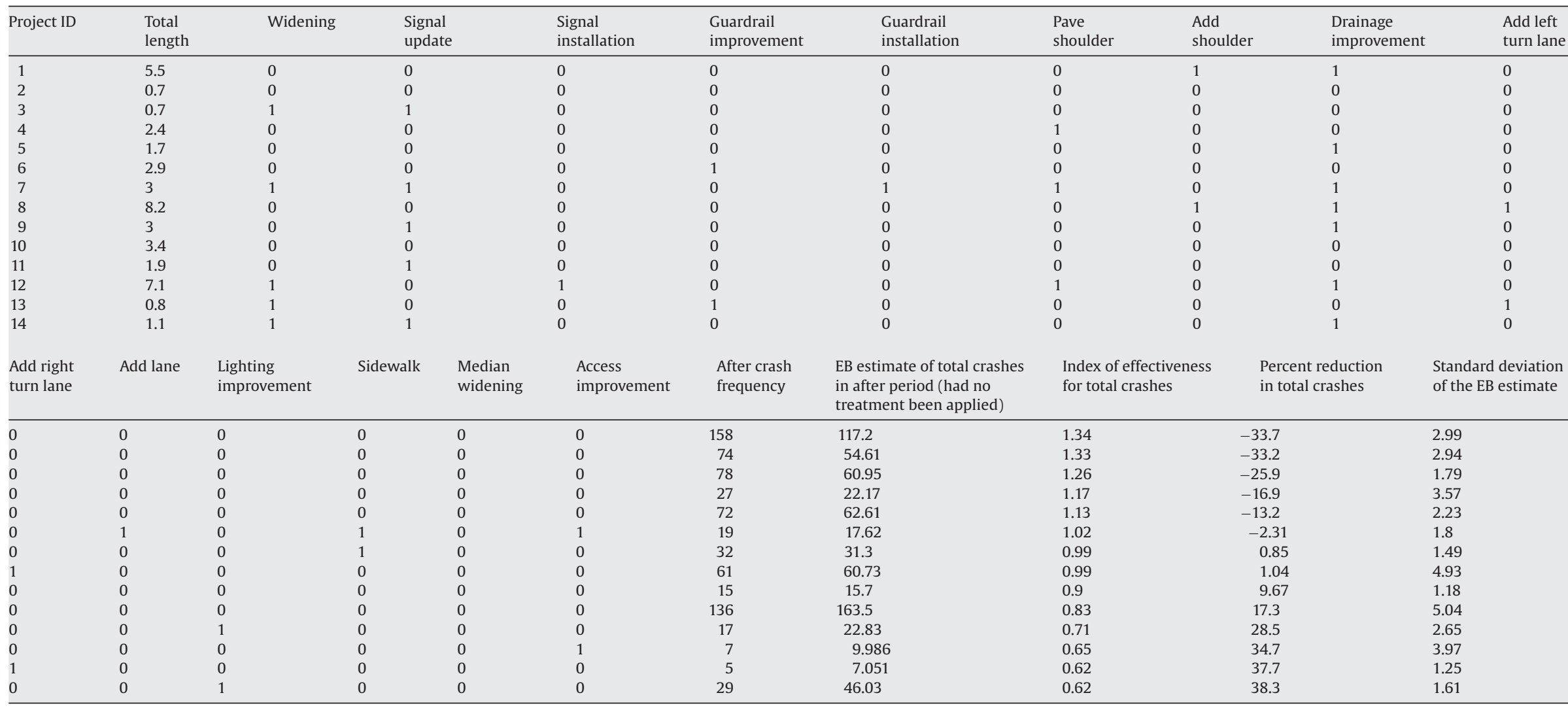

Positive values indicate that the safety improved and negative values indicate that the safety deteriorated in terms of reduction in total number of crashes. 


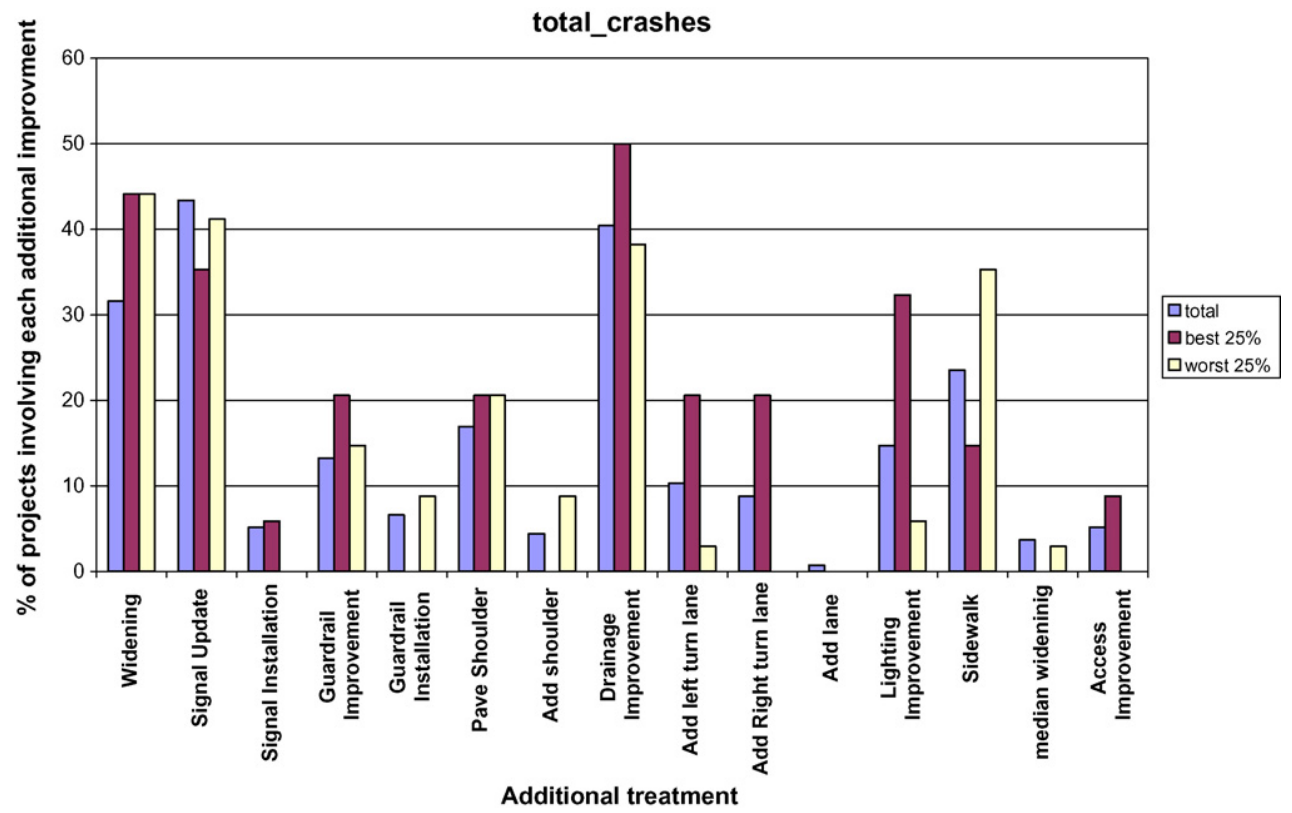

Fig. 2. Comparison of proportions (of project with each additional improvement) in best 25\%, worst 25\%, and all (100\%; 136 ) projects in terms of changes in total crashes.

It is worth acknowledging that the results shown in Figs. 2-4 are for better understanding with no statistical significance attached to it. Therefore, these preliminary comparisons between additional improvements were followed up with statistical tests to see if certain improvements are indeed associated with increased likelihood of a project being part of best or worst $25 \%$ projects. The Fisher's exact test is based on the frequency of cells in a ' $2 \times 2$ ' contingency tables. One-sided Fisher's test (carried out separately for each of the additional improvement) evaluates whether the presence of a particular improvement in a project increases the likelihood of that project falling in the best $25 \%$. Similar tests are also done for worst $25 \%$. The null hypothesis for this test is that there is no association between presence of an improvement with the project falling in best $25 \%$ or worst $25 \%$. The low $p$-values indicate sufficient evidence for rejection of the null hypothesis.

Table 8 shows the results of the Fisher's exact test. If an improvement has a low p-value corresponding to best $25 \%$ and high $p$-value corresponding to worst $25 \%$ then it may be considered a good improvement in terms of that corresponding crash group. If both $p$-values are either low or if both of them are high then no inference can be made. Additional improvements with low $p$-value (i.e., $\leq 0.15$ ) corresponding to best $25 \%$ and high $p$-value $(>0.15)$ corresponding to worst $25 \%$ have been highlighted in light shade indicating improvements with a positive impact on safety. Similarly, improvements with low $p$-value (i.e., $\leq 0.15$ ) corresponding to worst $25 \%$ and high $p$-value $(>0.15)$ corresponding to best $25 \%$ have been highlighted in dark shade

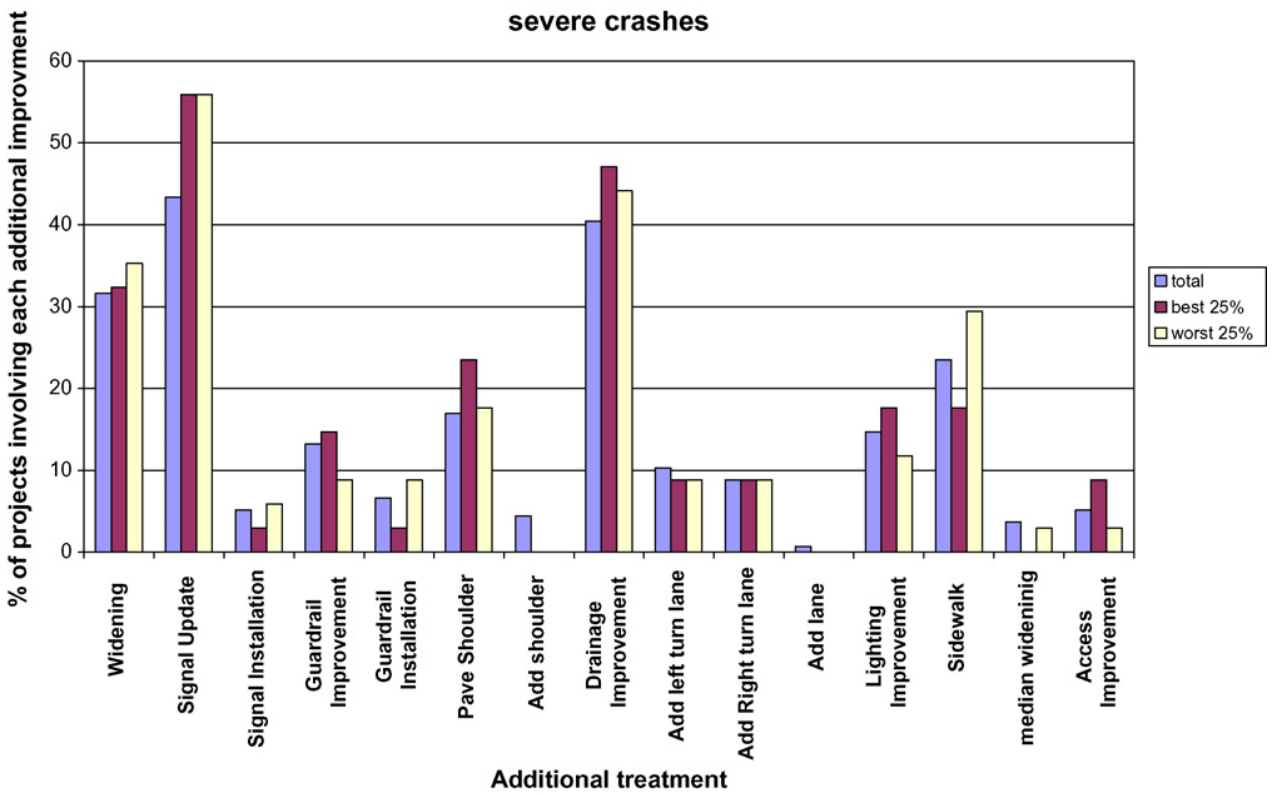

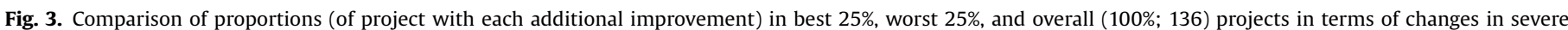
crashes. 


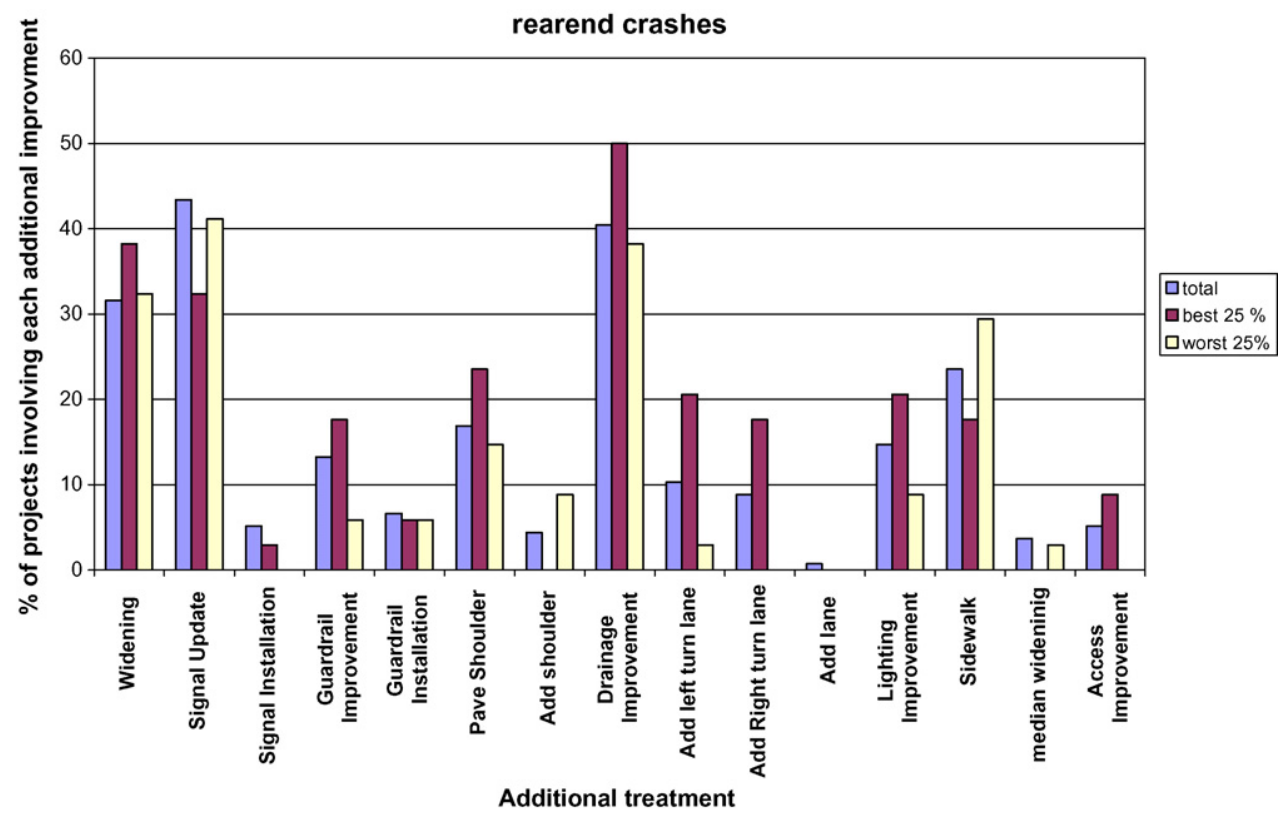

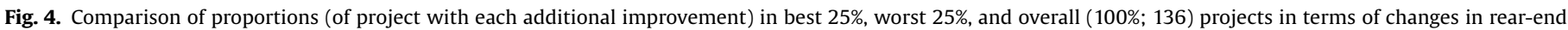
crashes.

indicating improvements that have a deteriorating impact on safety. Also, note that $p$-value of 1 in the table indicates that there were exactly zero projects involving corresponding improvement in the corresponding category (i.e., best $25 \%$ or worst $25 \%)$.

The results indicate that sidewalk is the only improvement that is associated with a project lying in the worst $25 \%$ ( $p$-value 0.05 ) and not significantly associated with the project lying in the best $25 \%$ ( $p$-value 0.95 ). It seems that none of the additional improvements carried out along with resurfacing have a significant impact on severe crashes. Paving shoulder and adding turn lanes (left and/or right) seem to be positively associated with projects being in best $25 \%$ in terms of rear-end crashes. Similarly guard rail improvements, drainage improvement, adding turn lanes (left and/or right), and lighting improvement are good practices in terms of all crashes.

It is interesting to note that none of the additional improvements, other than sidewalk improvements, increases the likelihood of a project lying in the worst $25 \%$ projects. Consequently, it may be inferred that getting additional improvements done when roadway surface are being repaved may be a good approach especially if it is found to be cost-effective.

Table 8

Fisher's exact test for identifying the best practices with resurfacing.

\begin{tabular}{|c|c|c|c|c|c|c|}
\hline \multirow[b]{3}{*}{$\begin{array}{c}\text { Additional } \\
\text { improvement }\end{array}$} & \multicolumn{2}{|c|}{ Total Crashes } & \multicolumn{2}{|c|}{ Severe Crashes } & \multicolumn{2}{|c|}{ Rear End Crashes } \\
\hline & \multicolumn{2}{|c|}{ Fishers exact test } & \multicolumn{2}{|c|}{ Fishers exact test } & \multicolumn{2}{|c|}{ Fishers exact test } \\
\hline & $\begin{array}{c}p \text {-value } \\
\text { best } 25 \%\end{array}$ & $\begin{array}{c}p \text {-value } \\
\text { worst } 25 \% \\
\end{array}$ & $\begin{array}{c}p \text {-value } \\
\text { best } 25 \%\end{array}$ & $\begin{array}{c}p \text {-value } \\
\text { worst } 25 \% \\
\end{array}$ & $\begin{array}{c}p \text {-value } \\
\text { best } 25 \%\end{array}$ & $\begin{array}{c}p \text {-value } \\
\text { worst } 25 \% \\
\end{array}$ \\
\hline Widening & 0.06 & 0.06 & 0.54 & 0.32 & 0.19 & 0.54 \\
\hline Signal Update & 0.90 & 0.69 & 0.07 & 0.10 & 0.94 & 0.69 \\
\hline Signal Installation & 0.56 & 1.00 & 0.87 & 0.54 & 0.86 & 1.00 \\
\hline $\begin{array}{c}\text { Guardrail } \\
\text { Improvement }\end{array}$ & 0.12 & 0.49 & 0.49 & 0.87 & 0.25 & 0.97 \\
\hline $\begin{array}{c}\text { Guardrail } \\
\text { Installation }\end{array}$ & 1.00 & 0.40 & 0.93 & 0.38 & 0.69 & 0.71 \\
\hline Pave Shoulder & 0.34 & 0.34 & 0.18 & 0.50 & 0.15 & 0.74 \\
\hline Add shoulder & 1.00 & 0.16 & 1.00 & 1.00 & 1.00 & 0.16 \\
\hline $\begin{array}{c}\text { Drainage } \\
\text { Improvement }\end{array}$ & 0.13 & 0.69 & 0.24 & 0.32 & 0.19 & 0.69 \\
\hline Add left turn lane & 0.03 & 0.99 & 0.73 & 0.71 & 0.03 & 0.99 \\
\hline $\begin{array}{c}\text { AddRight turn } \\
\text { lane } \\
\end{array}$ & 0.01 & 1.00 & 0.62 & 0.59 & 0.04 & 1.00 \\
\hline Add lane & 1.00 & 1.00 & 1.00 & 1.00 & 1.00 & 1.00 \\
\hline $\begin{array}{c}\text { Lighting } \\
\text { Improvement }\end{array}$ & 0.00 & 0.98 & 0.38 & 0.91 & 0.17 & 0.93 \\
\hline Sidewalk & 0.95 & 0.05 & 0.88 & 0.20 & 0.86 & 0.24 \\
\hline Median widening & 1.00 & 0.77 & 1.00 & 0.76 & 1.00 & 0.77 \\
\hline $\begin{array}{c}\text { Access } \\
\text { Improvement }\end{array}$ & 0.24 & 1.00 & 0.24 & 0.86 & 0.22 & 1.00 \\
\hline
\end{tabular}




\section{Concluding remarks}

This study assessed statewide resurfacing projects for multilane arterials. The SPFs estimated for all, rear-end and severe crashes on multilane arterials for this study not only included ADT, section length, number of lanes, and speed limit but are also developed separately for sections in urban, suburban and rural land use and different length groups.

The EB estimates for changes in safety (in terms of reduction in number of total, severe, and rear-end crashes) following the resurfacing projects showed that the improvement in safety was not correlated with lengths of the section resurfaced. The estimates of change in safety varied widely from project to project and even for the three crash groups. This variation in terms of severe crashes was not explained by the additional improvements involved in the projects. However, in terms of rear-end crashes resurfacing projects are likely to result in relatively higher improvement if paving shoulder and adding turning lanes are also part of the project.

In the future, the analysis may be extended to intersection improvements for identifying the best practices to be carried out with those projects. One interesting area of examination could be to assess associations between the characteristics of the resurfaced sections with the improvements that they achieve. Geographical information system based analysis may also be employed to examine if certain regions of a jurisdiction (state/county) are associated with the estimated improvements in safety.

\section{Acknowledgements}

The authors wish to thank the Florida Department of Transportation for funding this research. The authors would also wish to thank in no order Mr. Abhishek Das, Mr. Alexis Nevarez, and Mr. Ali Darwiche for their help in the data collection process.

\section{References}

Abdel-Aty, M., Radwan, E., 2000. Modeling traffic accident occurrence and involvement. Accident Analysis and Prevention 32 (5), 633-642.
Cleveland, D., 1987. Effect of resurfacing on highway safety, State-of-the-Art Report 6: Relationship between Safety and Key Highway Features: A Synthesis of Prior Research, Transportation Research Board, National Research Council, pp. 78-95.

Financial Management Database, FDOT, http://webapp01.dot.state.fl.us/ FinancialProjectSearch. Accessed December 2007.

Harwood, D., Bauer, K., Potts, I., Torbic, D., Richard, K., Kohlman Rabbani, E., Hauer E., Elefteriadou, L., 2003. Safety effectiveness of intersection left- and rightturn lanes. Transportation Research Record 1840, Transportation Research Board National Research Council, pp. 131-139.

Hauer, E., 2001. Overdispersion in modelling accidents on road sections and in empirical Bayes estimation. Accident Analysis and Prevention 33, 799808.

Hauer, E., 1997. Observational Before-After Studies in Road Safety. Pergamon/Elsevier Science, Inc., Tarrytown, NY.

Hauer, E., Terry, D., Griffith, M., 1994. Effect of resurfacing on the safety of two-lane rural roads in New York State. Transportation Research Record 1467, Transportation Research Board, National Research Council, pp. 30-37.

Hughes, W., Prothe, L., McGee, H., Hauer, E., 2001. Impacts of resurfacing projects with and without additional safety improvements. In: NCHRP Research Results Digest 255. Transportation Research Board.

McGee, H., Huges, W., Daily, K., 1995. Effect of highway standards on safety. NCHRP Report 374, Transportation Research Board, National Research Council, Washington, $\mathrm{DC}$.

Noyce, D., Talada, V., Gates, T., 2006. Safety and operational characteristics of twoway left-turn lanes: final report. Minnesota Department of Transportation.

Persaud, B., Lyon, C., 2007. Empirical Bayes before-after safety studies: lessons learned from two decades of experience and future directions. Accident Analysis and Prevention 39, 546-555.

Persaud, B., Retting, R., Lyon, C., 2004. Crash reduction following installation of centerline rumble strips on rural two-lane roads. Accident Analysis and Prevention 36, 1073-1079.

Persaud, B., 1990. Black Spot Identification and Treatment Evaluation. Ministry of Transportation, The Research and Development Branch, Ontario.

Project Contract Documents, FDOT, http://webapp01.dot.state.fl.us/ enterpriseinformationportal/edms/documentsearch.asp. Accessed February 2008.

Project Plans, FDOT, http://bilby.imageapi.com/dot/main.aspx. Last Accessed February 2008.

2001. RCI Features and Characteristics Handbook. Florida Department of Transportation, Transportation Statistics Office, Tallahassee, FL.

Shen, Q., 2007. Development of Safety Performance Functions For Empirical Bayes Estimation of Crash Reduction Factors, Ph.D Thesis. Florida International University, $206 \mathrm{p}$.

The GENMOD Procedure. SAS Institute Inc., Cary, North Carolina, USA http://support.sas.com/onlinedoc/913/docMainpage.jsp Accessed May, 2008. 